\title{
Role of Power Electronics Devices in Grid Integration with Renewable Energy Source (Wind) and Challenges

\author{
Apar Chitransh, Surbhi Gupta
}

\begin{abstract}
We know that to growing population in India this time to use the renewable source to generate the electricity and most of the government and private companies do this very confident way. We know that the main renewable energy sources in our word is sun and wind with the help of sun and wind most of the company are situated the plant at that places where the efficiency and generation of electricity is more and more accuracy and fulfill the requirement of the electricity demand. Where this is depending upon the mostly to the renewable energy there to connect this farm to the grid system the power electronics devices play a very important role. We can say that yes wind energy and solar energy is the future management which is fulfill the requirement of the electricity generation demand. In this paper we discuss the different type of power electronics devices which is used in wind power generation system. In this paper we also discuss about some type of challenged which is coming when these farms connected to the grid.

Keyword: Wind Turbine Technology, Power Electronics, Grid Challenges In Wind, Flywheel, Smes.
\end{abstract}

\section{INTRODUCTION}

As we know that the increasing the renewable energy sources and distributed also it require that some new technology is coming in to the picture which is good for implemented the wind energy in to the grid system. For more integrated with the electrical grid to renewable energy the new modern power electronics play a very important role also it helps to improve the reliability. In last few year it saw that the new modern power electronics is very successful to connected with the electrical grid and yes under this the electrical grid is fast evolution due to two factor 1 . Semiconductor switches and 2. Real time computer control. The semiconductor switch is useful the handling the high power and 2 one is good for control the complex power. Some time the MPPT is coming also in to the picture. And this technology is good for cost effectiveness and for converter.

In this paper we discuss about the all type of modern power electronics device use to connected the wind energy system in to the electrical grid.

Manuscript received on 29 May 2021 | Revised Manuscript received on 06 June 2021 | Manuscript Accepted on 15 June 2021 | Manuscript published on 30 June 2021.

* Correspondence Author

Apar chitransh*, M.e. Electrical, Department of Electrical Engineering, Chandigarh University, Punjab, India. Email: achitransh987081@gmail.com

Dr. Surbhi gupta, Associate Professor, Department of Electrical Engineering, Chandigarh University, Punjab, India. Email: surbhi.e9023@cumail.in

(c) The Authors. Published by Lattice Science Publication (LSP). This is an open access article under the CC-BY-NC-ND license (http://creativecommons.org/licenses/by-nc-nd/4.0/)
This paper divided in the different section where we discuss the wind turbine technology, current wind turbine technology, grid connected standards for wind farm, grid coordinate rule, impact of grid, challenges of wind integration.

\section{WIND TURBINE TECHNOLOGY}

Variable Speed Wind Turbine: -

In last 15-year wind energy system designed by the aerodynamic, power electronics devices and mechanical drive train and that's why it growing percentage gone to approximate $30 \%$. A new technology is introduced in the wind energy profile system that is variable speed wind turbine system in this system that is depend upon the speed of wind and its roughness factor which is captured from the wind. $5 \%$ of energy is captured by this technology in the annual. It has less mechanical, and less fluctuation because the rotor of turbine work as a flywheel and for this reason the active and phantom power generation is easily controlled. When the reactive power varied in variable wind speed then the grid voltage to be controller easily. The main disadvantage of this turbine that it collects the more component to work properly. The overall cost of this type of turbine is $7 \%$ of the total cost of wind turbine. Wind generation system process is different from the normal electricity generation system, most of the case electricity generation system is use the synchronous generator and this difference is shown when this connected to the integration with the electrical power system. this type of wind turbine is specially designed to operate a wide range of wind system. it directly connected to the fixed speed of the wind turbine where rotor speed is almost constant. It depends upon the tip speed ration.

\section{Current Wind Speed Technology: -}

Where the variable wind speed turbine can be achieved the decoupling of electrical grid frequency and mechanical rotor frequency system there the power electronics devices like converters which is combined with the advanced control system.

\section{Variable Speed Concept with Doubly Fed Induction} Generator: -

With DFIG, it converts the rotor winding, while the stator winding is directly connected to the grid. In this speed concept it decouples the mechanical frequency and electrical frequencies and also vary with the rotor frequency.

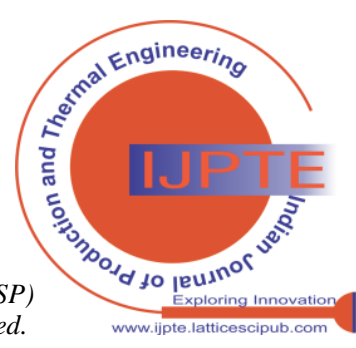


The advantage of this turbine is that it cannot operate with the zero means full range of the rated speed. It works on the principle of the ratio between the size of the converter and the wind turbine rating is half of the rotor speed. As it works on the power converter system it is similar to the reactive power. In fig we saw that the converter consists of the two three phase ac-dc converter and dc battery. Also, it consists the reversible current switch arm and it operating this in opening and closing in same time. Mostly it consists the IGBT switch and diode also. for connected to the inverter to the grid it uses the passive filter. In this technology where the efficiency of the system decreases when the slip increase.

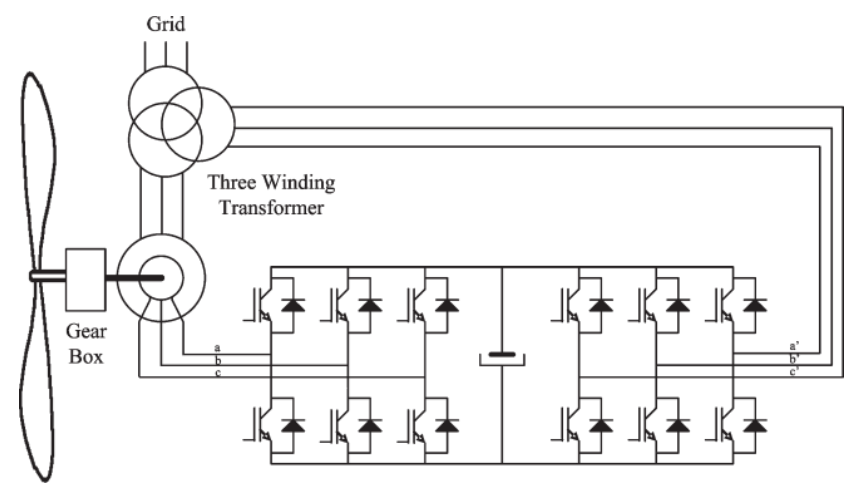

Fig:1. Single doubly fed induction machine with two fully controlled ac-dc power converters.

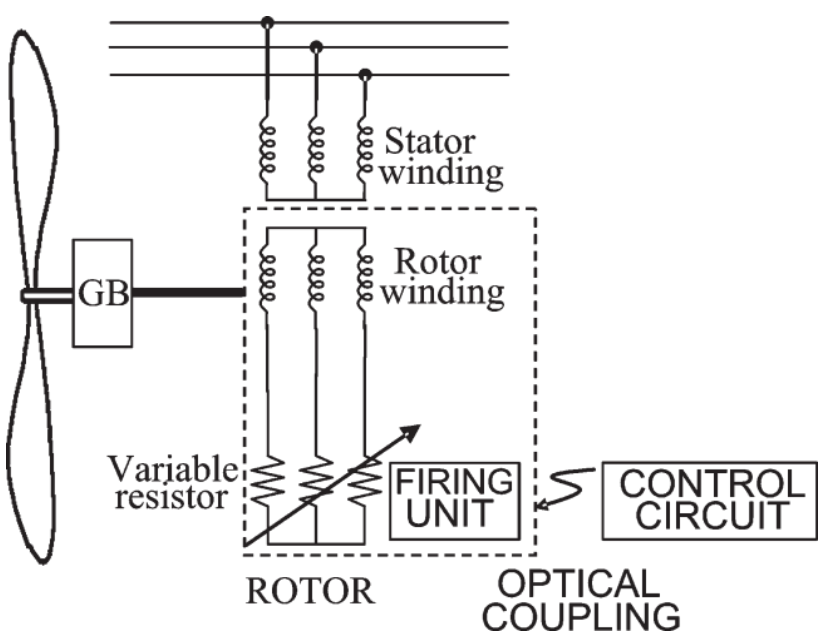

Fig:2. Single doubly fed induction machine controlled with slip power dissipation in an internal resistor.

Variable Speed Concept Utilizing The Full Power Converter: -

The majority of this concept is this that this is consists the no. of synchronous generator system, also some time it uses the induction generator in different case. In this case the generators are decouple from the grid. first the energy is rectified by the power electronics device into the dc link then this is converted to the ac energy for the grid. For removing the gear box in to the turbine most of the advantage are seeing as like it reduce losses, and low cost. For elimination of the component the reliability of the system has been increased. In fig the full power converter shows. The three-phase controller work as a drive controller in a machine side for using the vector controlling strategy. Also, the three-phase converter are used for the converting the energy to the grid side and also control the active and reactive power which is delivered to the grid side. This converter is also used for improving the power quality at the grid side and yes it keeps some amount of THD. It connected with the dc link which is stored the energy in capacitor in form of charge and delivered to the grid. As alternative component we can use instead of synchronous generator we use the induction generator and instead of three phase converter we can use the chopper and three phase diode rectifiers. The step-up chopper we can use for the adapt the rectifier voltage. For determine the voltage of inverter the generation system is work according to the ideal current sources. Step-up controller also used as a control the machine torque.

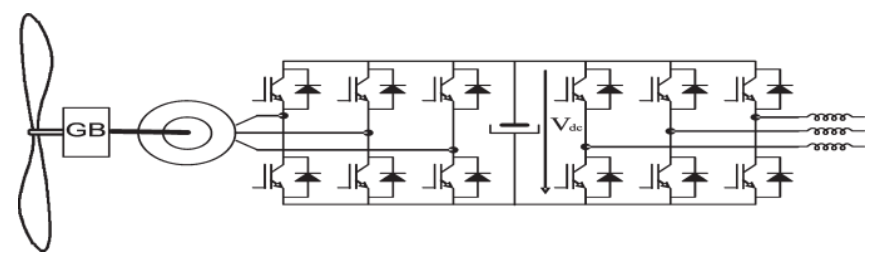

Fig: 3. Double three-phase VSI.

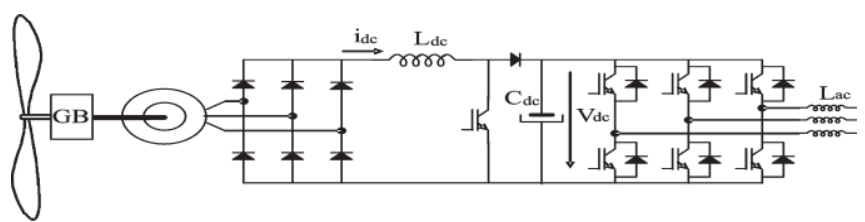

Fig: 4. Step-up converter in the rectifier circuit and full power inverter topology used in wind-turbine applications.

\section{SEMICONDUCTOR TECHNOLOGY: -}

For improve the power quality and reliability of the system the wind energy system is directly connected with the power electronics semiconductor devices for lower price and better electrical characteristics. Insulated gate bipolar transistor (IGBT) is main component for the wind turbine application. This technology is work on the high power (6KV-1.2KA) and also it has high completion with the GTO in thyristor family. For a research criterion the IGBT has been developed a modern mechanical integration of GTO which is allow in the large operation and which is a hard drive circuit. In comparison of the IGBT the new technology coming in to the picture that is IGCT (integrated gatecommuted thyristor). Which is used for the switching electrical current in industrial application. The basic difference between the IGBT and IGCT is that it has higher switching frequency with comparison of IGCT. And they introduced the distortion of the grid side. IGCT works as a disk like device and IGBT acts like modular devices. The main advantage of the IGCT VS IGBT is that they have lower On-stage voltage drop.

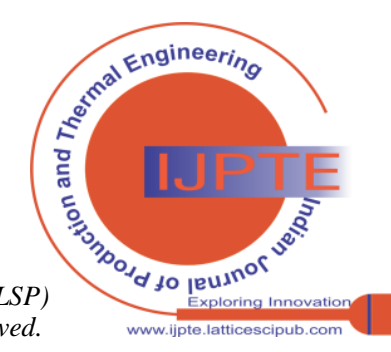




\section{Power Quality Requirement For Grid Connected Wind Turbine: -}

For integration of grid and grid impact system is the main case of wind turbine and yes, it is shown that the power quality of the wind turbine is very poor to improve the power quality of wind farm then we use the power electronics device like FACT devices. Measurement show that the quality of the wind energy system is improved in last few year by using the power electronics devise system. The use of variable speed turbine in the wind farm means that it carries the harmonics and inter-harmonics in to the system. The international electrotechnical commission confirm the standard on power quality of wind energy system in 1995 as a part of wind turbine standardization. In 1998 it has been part of the power quality requirement for grid connected system. This methodology having the various steps 1 . To check the flicker analysis of the system. and 2, switching the operations. In this operation we can measure the voltage and current transient 3 . Is the harmonics analysis which is coming by the use of fast Fourier transform (FFT). The wind farm is not producing the harmonics in to the system also it producing the interharmonics system. the harmonic is operating on the $50 \mathrm{HZ}$ frequency level.

\section{Transmission Technology for the Future: -}

The main installation of wind farm is near the sea. The sea is a very goof place to installed the wind farm energy in offshore installation system. In comparison of the off shore and on shore the off shore wind energy system is the most reliable energy system in the win energy system. in comparison of the generation of the energy the off shore is $50 \%$ more generate the electricity than the on shore. because the on shore is installed in the flat areas and off shore is installed in the mostly in sea area. In construction and installation of the off shore wind farm is $50 \%$ more require energy but it has a longer life than the on shore, its life is approximate 25 to 30 years. HVAC transmission line is most effectiveness and simple solution which is connected to the grid to wind farm. In offshore area the wind cable is higher than the distribution electricity transmission overhead lines. Because the standard height criteria are coming to the picture. For this reason, the high voltage Dc line are connected to the wind farm to grid with the effectively transmit the energy. It transmits the $100 \mathrm{~km}$ or power levels of between 200 and 900MW. It has many advantages as like 1. Sending and receiving end frequency is independent.2. offshore installation is isolated from the mainland. 3. Power of cables are low. 5. Power of transmission is high. The HVDC transmission line is based on the current source converter with connected to the thyristor as like FACT devices so that is called the line commuted converters. With connected to the more consumer side it needs the AC grid system which is connected the wind farm to the grid system. the main disadvantage of HVDC transmission system is the lack of the provide the independent control in active and reactive power. Voltage source converter based HVDC transmission system are gain the more reliability for the wind farm and grid system. voltage source converter based HVDC is not require any type of offshore and onshore ac network, in this system the active and reactive power can be controller independently.
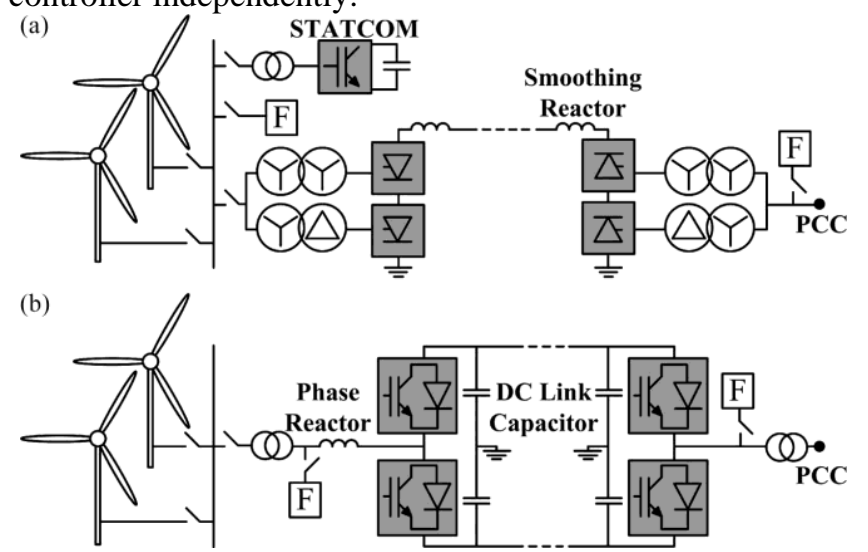

Fig: 5. Two HVDC transmission solutions. (a) Classical LCC-based system with STATCOM. (b) VSC-based system.

\section{GRID INTEGRATION CHALLENGES}

\section{Output Power Prediction: -}

Before the installation the wind farm on off shore and on shore it is very important that we must take the description where the wind farm installed. Which is suitable for estimated the cost for installing it. It is very necessary to predict the wind speed because the output if the wind energy is depending upon the wind speed and its roughness factor. The roughness factor is also relying to the $0.2 \mathrm{~cm}$ to $0.02 \mathrm{~cm}$. mostly the wind prediction is depending upon the on shore and off shore system. in on shore system the wind farm is installed to far way to the house and roads also wind resources and available in bulk amount. In off shore the wind turbine is located in the faraway to land and harbor. Navigation routes and subsea cable also. The wind profile is based on the logarithmic at high wind speed. Also, it depends on the height of the boundary layer as we saw on the slide. Wind height is more at the night when the temp is increase during night. There is no ideal strategy for the prediction of wind energy there is one mathematically analysis that is forecasting of wind energy. Depending on the operating need, it has to be divided in to four categories 1. Intra hour 2. Short term 3. Medium term 4. Long term. This has to standard length (1-60min) for intra hour, (16hour) for short term, (day head) for medium term and last for long term it includes the (season, week). The forecasting method is divided in two categories 1. Deterministic forecasting 2. Uncertainty analysis. This deterministic forecasting has a different category: physical, statical, intelligent, hybrid. And uncertainty analysis has probability, prediction, risk indices.

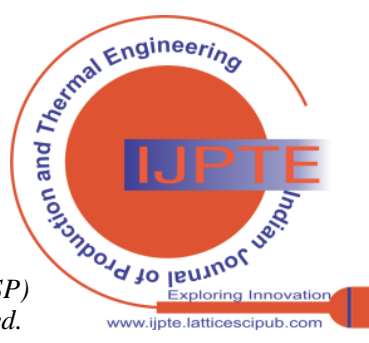




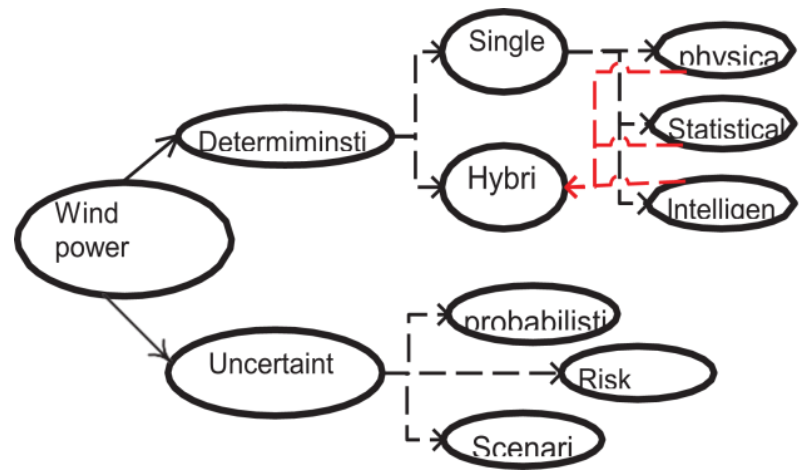

Fig: 6. Wind prediction approaches

\begin{tabular}{|l|l|l|}
\hline s.no & Time scale & Usage \\
\hline 1. & $5-60$ minutes & $\begin{array}{l}\text { Regulation of real } \\
\text { time dispatch decision }\end{array}$ \\
\hline 2. & $1-6$ hour & $\begin{array}{l}\text { Load following, next } \\
\text { operating unit }\end{array}$ \\
\hline 3. & Day head & $\begin{array}{l}\text { Economic dispatch, } \\
\text { unit commitment }\end{array}$ \\
\hline 4. & $\begin{array}{l}\text { Seasonal/ long } \\
\text { term }\end{array}$ & Resource's planning \\
\hline
\end{tabular}

\section{Reactive power and Voltage Support: -}

To generate the wind energy system the machine is used is induction generator instead of synchronous generator. To consume the reactive power, it necessary to use the induction generator. It is very tough to consume the reactive power we did not use the synchronous generator. By the help of PCC point of common coupling set the limit it is necessary to reduce the amount of reactive power. To control the most of the flow of reactive power we use to improve the power quality, STATCOM model in wind farm. The capacity of wind plant it is more important to reduce the reactive power these factors are depend upon grid strength and the transmission line system. to improv the voltage profile with the help of processing with the generator and absorbing the reactive power in flexible side of grid.

\section{Impact of Frequencies: -}

when the alternation occurs when the turbine rotates an electromagnet side then the array of large copper side generate electrically thermally. The rate of this alternation is called the electrical frequency. When the wind generate power transmit to the grid side it reduces the overall system inertia.

\section{Impact of the Harmonics/ Power Quality Issue: -}

when the wind farm connected to the grid system that introduced at the different level the harmonics. To analyze the harmonics system we need to develop, we need to considered that element which is consume that emission. The source of harmonics in the wind power plant is most commonly is cable but include this most of the element have some other equipment which increase the harmonics that element like transformer and capacitors and filter, power electronics device and power factor correction device. Due to this increasement of the harmonics increase the cost of the generating unit and too much loss occurring in to the productivity. For increasing the productivity, it uses the larger and heavily motor to generate more electricity. If we talking about the power quality of a grid system that is a combination of a power quality system, frequency and harmonic contain, reliability. It is defined as like which system which have stable case of power system quality and zero distortion system. power quality deal with the standard industry application. The source of poor quality is grid having a nonlinear load, arching load, reactive load, unstable load. Due to the poor power quality the energy meter gives the wrong reading and protective relay got damaged. Due to the nonlinear load the third harmonics generated in to the grid system due to this the neutral wire burning out.

\section{CONCLUSION}

In this paper we discuss about the all-power electronics role to established the wind farm and connected to that with the grid system. the new modern power electronic technology plays a very important role to integrated renewable energy source to the grid system. it is true that the power electronics devices is useful for the taking the highest transferring the power through the turbine and also optimization of power system, it reduce the harmonics and doing the control reactive power and minimize the harmonics distortion system. in this paper we also discuss about the modern trend to transmit the wind energy system and see the HVDC link is very useful to transmit this. Also, in this paper we discuss some type of grid challenges like harmonic impact and output power prediction and we seen that forecasting is very necessary to installed any type of wind farm.

\section{REFERENCES}

1. IRENA, "Wind energy," 2019. [Online]. Available: https://www.irena. org/wind \

2. World Wind Energy Association, “ Wind Power Capacity Worldwide Reaches 597 GW, 50,1 GW added in 2018,” 2018, Accessed 2019-09-17. [Online]. Available: https://wwindea.org/blog/2019/02/25/ wind-power-capacityworldwide-reaches-600-gw-539-gw-added-in-2018/

3. Iea, "Market report series: Renewables 2018 - analysis," Oct 2018. [Online]. Available: https://www.iea.org/reports/renewables-2018

4. M. Singh and S. Santoso, "Dynamic models for wind turbines and wind power plants," National Renewable Energy Lab.(NREL), Golden, CO (United States), Tech. Rep., 2011. [CrossRef]

5. Australian Energy Market Operator, "Wind turbine plant capabilities report-2013 wind integration studies," 2013.

6. International Electrotechnical Commission. Technical Committee 88, Wind Turbines: Electrical Simulation Models Wind Turbines, ser. International standard. International Electrotechnical Commission, 2015, no. pt. 27, no. 1. [Online]. Available: https://books.google.com.sa/ books?id=t5HBtAEACAAJ

7. A. Ellis, Y. Kazachkov, E. Muljadi, P. Pourbeik, and J. SanchezGasca, "Description and technical specifications for generic wtg models - a status report," in 2011 IEEE/PES Power Systems Conference and Exposition. IEEE, 2011, pp. 1-8. [CrossRef]

8. Y. Kazachkov and S. Stapleton, "Does the generic dynamic simulation wind turbine model exist?" Proc. WindPower 2005, 2005.

9. N. W. Miller, J. J. Sanchez-Gasca, W. W. Price, and R. W. Delmerico, "Dynamic modeling of ge 1.5 and $3.6 \mathrm{mw}$ wind turbinegenerators for stability simulations," in 2003 IEEE Power Engineering Society General Meeting (IEEE Cat. No. 03CH37491), vol. 3. IEEE, 2003, pp. 1977-1983.

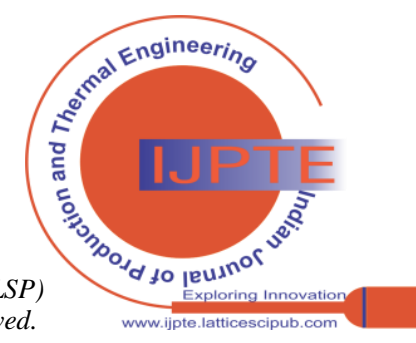


10. K. Clark, N. W. Miller, and J. J. Sanchez-Gasca, "Modeling of ge wind turbine-generators for grid studies," GE energy, vol. 4, pp. 0885-8950, 2010.

11. S. Heier, Grid Integration of Wind Energy Conversion Systems. Hoboken, NJ: Wiley, 1998.

12. G. L. Johnson, Wind Energy Systems. Englewood Cliffs, NJ: PrenticeHall, 1985.

13. S. Muller, M. Deicke, and R. W. De Doncker, "Doubly fed induction generator systems for wind turbines," IEEE Ind. Appl. Mag., vol. 8, no. 3, pp. 26-33, May/Jun. 2002. [CrossRef]

14. F. M. Hughes, O. Anaya-Lara, N. Jenkins, and G. Strbac, "Control of DFIG-based wind generation for power network support," IEEE Trans. Power Syst., vol. 20, no. 4, pp. 1958-1966, Nov. 2005. [CrossRef]

15. M. Orabi, F. El-Sousy, H. Godah, and M. Z. Youssef, "Highperformance induction generator-wind turbine connected to utility grid," in Proc 26th Annu. INTELEC, Sep. 19-23, 2004, pp. 697704.

16. J. M. Peter, "Main future trends for power semiconductors from the state of the art to future trends," presented at the PCIM, Nürnberg, Germany, Jun. 1999, Paper R2 667-671.

17. H. Grüning et al., "High power hard-driven GTO module for 4.5 kV/3 kA snubberless operations," in Proc. PCI Eur., 1996, pp. 169183.

18. E.ON Netz Grid Code. Bayreuth, Germany: E.ON Netz GmbH, Aug. $1,2003$.

19. D. Foussekis, F. Kokkalidis, S. Tentzevakis, and D. Agoris, "Power quality measurement on different type of wind turbines operating in the same wind farm," presented at the EWEC (Session BT2.1 Grid Integration), Madrid, Spain, Jun. 16-19, 2003.

20. Electromagnetic Compatibility, General Guide on Harmonics and Interharmonics Measurements and Instrumentation, IEC Standard 61000-4-7, 1997

\section{AUTHOR PROFILE}

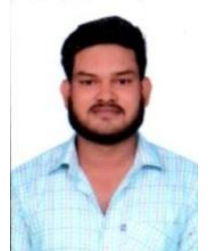

Apar chitransh, is pursuing M.E. in electrical engineering in power system specialization in Chandigarh university. His area of interest in wind energy system and power electronics devices and power system, quantum computing. He published his work without copy right in various journals and preparing for join the conferences also. till now he published more than 5 papers in international journal regarding the energy consumption and wind energy related paper. Also, member of IEEE.

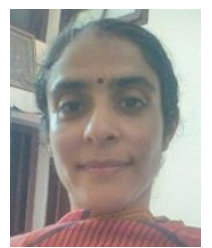

Dr.Surbhi Gupta, obtained her B. Tech from Kurukshetra University, Kurukshetra (Haryana) India. Received her Masters degree from Punjab Technical University, Jalandhar (Punjab) India and Doctorate degree in Electrical Engineering from PEC Chandigarh India. Has more than 18 years of teaching experience and has guided many research scholars. 